\title{
Determination of melting point of vegetable oils and fats by differential scanning calorimetry (DSC) technique
}

\author{
By Renata Tieko Nassu* and Lireny Aparecida Guaraldo Gonçalves
}

Laboratório de Oleos e Gorduras - Faculdade de Engenharia de Alimentos (FEA) - Universidade Estadual de Campinas (UNICAMP), Caixa Postal 6091 CEP 13081-970, Campinas, SP, Brazil.

* To whom correspondence should be addressed. New address: Centro Nacional de Pesquisa da Agroindústria Tropical (CNPAT)/EMBRAPA - Rua Dra. Sara Mesquita, 2270. CEP 60511 -110, Fortaleza,

CE, Brazil. e-mail: renata@ cnpat.embrapa.br

\section{RESUMEN}

Determinación del punto de fusión de aceites y grasas vegetales por técnica de calorimetría diferencial de barrido (DSC).

El punto de fusión de grasas es usado para caracterizar aceites y grasas, y está relacionado con sus propiedades físicas, tales como dureza y comportamiento térmico. El presente trabajo muestra la utilización de la técnica de Calorimetría Diferencial de Barrido (DSC) en`la determinación del punto de fusión de grasas. En comparación con el punto de ablandamiento (AOCS método Cc 3-25), los valores de DSC fueron más altos que los obtenidos por los métodos de AOCS. Esto ha ocurrido debido al hecho que los valores obtenidos por la técnica de DSC fueron tomados cuando la grasa había fundido completamente. DSC fue también útil para determinar puntos de fusión de aceites líquidos, tales como los de soya y algodón.

PALABRAS-CLAVE: Calorimetría Diferencial de Barrido (DSC) - Grasa vegetal - Punto de ablandamiento - Punto de fusión.

\section{SUMMARY}

Determination of melting point of vegetable oils and fats by differential scanning calorimetry (DSC) technique.

Melting point of fats is used to characterize oils and fats and is related to their physical properties, such as hardness and thermal behaviour. The present work shows the utilization of DSC technique on the determination of melting point of fats. In a comparison with softening point (AOCS method Cc 3-25), DSC values were higher than those obtained by AOCS method. It has occurred due to the fact that values obtained by DSC technique were taken when the fat had melted completely. DSC was also useful for determining melting point of liquid oils, such as soybean and cottonseed ones.

KEY-WORDS: Differential Scanning Calorimetry (DSC) Melting point - Softening point - Vegetable fat.

\section{INTRODUCTION}

Melting point of fats is measured by various methods. These include Wiley melting point (AOCS
Method Cc 2-38) (AOCS, 1988), open capillary slip point, softening point (AOCS method Cc 3-25) (AOCS, 1988), ring and ball methods and automated techniques such as Mettler dropping point and Elex apparatus. Several authors compared methods. usually applied with another ones, in relation to the methods themselves and temperature procedures. Kanematsu et al., (1979a and 1979b), used Mettler dropping point and tested conditions for measurement, comparing values obtained by Mettler dropping point, softening point from Japanese standard, clear point and Wiley melting point with various fats. Close correlations were found between these methods. Open-tube melting point using Elex automatic apparatus was compared with the conventional method by Kanematsu et al., (1981). Results showed that the values obtained did not show statistically significant differences. Deman et al., (1983) compared several methods for determination of melting point using various fats and tested the reproducibility of these methods. Reproducibilities of the Mettler dropping point and softening point were considered excellent and for slip point, poor. Kawada et al., (1985) proposed melting point determination by another methods, such as ring and ball methods.

Many melting point measurement methods can be grouped in different ways. As parameters for measuring it, some methods determine the point of complete melting of all crystalline material while others use a point farther removed from there and are called softening, slipping or dropping points. Subjective interpretation of the endpoint by the operator or objective indications are used. Some methods depend upon manual controls; others emply a certain degree of automation. In this group, modern instrumentation has shown the way for possible improvements. The use of automatic temperature control, linear heating rates and objective endpoint determinations promise an improvement in the precision of melting point tests (Mertens, 1973). Differential Scanning Calorimetry 
(DSC) is an alternative, being one of the most used techniques for studying thermal behaviour of various foods components. Melting point obtained by DSC is generally considered as the onset temperature, the inflection point of melting curve and solid line. Deman et al., (1991) consider melting point as the peak temperature calculated from a DSC melting curve. In this referred study, temperature measured at the end of melting curve obtained by DSC was considered as the real melting point, where the melting phenomenon finishes, when all crystals in solid state became liquid. Siew et al., (1982) concluded that melting point is essentially determined by the hard fraction of stearins, indicated by the major peak. Chaisery \& Dimick (1995), in a study of crystallization of cocoa butter, measured melting point by DSC of low and high melting fractions, considering onset melting temperature. In a study of effect of cooling and heating rates variation, Cebula \& Smith (1991) measured melting point of pure triglycerides, also considering the onset temperature.

In this study, final melting temperatures obtained by DSC technique were compared with softening point (AOCS method Cc 3-25) (AOCS, 1988) values for various vegetable oils and fats.

\section{EXPERIMENTAL}

\subsection{Material}

14 different types of oils and fats were used: soybean oil, cottonseed oil, palm oil, palm olein, palm stearin, babassu oil and hydrogenated oils (soybean, two types; palm oil, cottonseed oil and babassu oil), palm kernel oil, palm kernel stearin and intersterified cottonseed oil. The samples were gently supplied by Gessy Lever Ltda. (Valinhos, SP) and Refinadora de Oleos Brasil (Sao Caetano do Sul, SP).

\subsection{Fatty acid compositions of samples}

Fatty acid composition was done through analysis of methyl esters by gas-liquid chromatography. The instrument used was a Perkin Elmer Sigma 3B gas-liquid chromatograph with ionization detector and the results were obtained by a Perkin Elmer integrator $\mathrm{LCl}$ - 100. The methyl esters were obtained according to Hartman \& Lago (1973).

\subsection{Melting point measurement of samples}

Melting point of samples were measured by Softening point [AOCS method Cc 3-25 (1988)] and by DSC, as described. The instrument used was a

Perkin Elmer DSC7 Differential Scanning Calorimeter. Nitrogen was the carrier gas and calibration was done with indium, after checking the operation with distilled, deionized water. $10-15 \mathrm{mg}$ of sample were enclosed in hermetically sealed aluminum pans and run against air (empty pan) as reference. DSC melting curves were obtained according to Dodd \& Tonge (1987). Samples were heated to $80^{\circ} \mathrm{C}$ for 5 minutes, cooled at $10^{\circ} \mathrm{C} / \mathrm{min}$ to $-50^{\circ} \mathrm{C}$, holding at this temperature for 5 minutes to crystallize the sample. After this procedure, melting curves were recorded from initial temperature to $80^{\circ} \mathrm{C}$ at a heating rate of $10^{\circ} \mathrm{C} / \mathrm{min}$. The resulting DSC data was analyzed by peak program and peak temperature, onset temperature and melting temperature were recorded. Melting temperature was considered as the temperature at the end of the curve, when melting has completed.

\section{RESULTS AND DISCUSSION}

Fatty acid composition of the samples can be seen in table I. Values showed the great variability of the samples, which influences melting point values and the shape of DSC melting curves.

\section{Table I}

Fatty acid composition of vegetable oils

\begin{tabular}{|c|c|c|c|c|c|c|c|c|c|c|c|}
\hline Sample & C8:0 & $\mathrm{C10:0}$ & C12:0 & C14:0 & C16:0 & C16:1 & C18:0 & C18:1 & C18:2 & C18:3 & C20:0 \\
\hline SON & - & - & - & 0.12 & 11.41 & 0.11 & 9.51 & $\begin{array}{c}22.31 \\
49.21(\mathrm{a})\end{array}$ & $\begin{array}{c}2.05 \\
4.84(b)\end{array}$ & 0.24 & 0.18 \\
\hline SOB & - & - & - & 0.12 & 11.16 & 0.11 & 13.04 & $\begin{array}{c}35.02 \\
36.28(a)\end{array}$ & $\begin{array}{c}0.91 \\
2.66(\mathrm{~b})\end{array}$ & 0.25 & 0.44 \\
\hline AGH & - & - & - & 0.84 & 23.31 & 0.74 & 3.36 & 59.39 & $\begin{array}{c}1.12 \\
10.11(b)\end{array}$ & 0.01 & $\begin{array}{c}0.25 \\
0.86(c)\end{array}$ \\
\hline AGI & 5.34 & 4.25 & 35.89 & 13.30 & 11.06 & - & 23.67 & 3.77 & 2.71 & - & - \\
\hline PMD & - & - & 0.46 & 0.82 & 38.23 & - & 5.32 & 42.47 & 12.19 & 0.10 & 0.39 \\
\hline PME & - & - & - & 0.80 & 49.83 & - & 6.59 & 32.62 & 9.28 & 0.50 & 0.37 \\
\hline PMO & - & - & - & 0.63 & 35.43 & - & 5.08 & 44.53 & 13.35 & 0.59 & 0.37 \\
\hline PMH & - & - & - & 0.68 & 40.22 & - & 56.30 & 2.07 & $\begin{array}{c}0.19 \\
0.52(\mathrm{~b})\end{array}$ & 0.01 & - \\
\hline PKR & 4.35 & 3.57 & 48.71 & 16.34 & 8.15 & - & 2.34 & 14.30 & 2.22 & - & - \\
\hline PKE & 2.62 & 3.02 & 54.85 & 21.06 & 8.35 & - & 2.47 & 6.68 & 0.94 & - & - \\
\hline BBD & 6.01 & 5.11 & 43.87 & 16.30 & 9.04 & - & 3.51 & 13.73 & 2.43 & - & - \\
\hline BBH & 5.90 & 5.07 & 42.74 & 15.54 & 9.08 & - & 15.69 & $\begin{array}{c}2.02 \\
2.85(\mathrm{a})\end{array}$ & 1.12 & - & - \\
\hline
\end{tabular}

SON-hydrogenated soybean oil type "N"; SOB-hydrogenated soybean oil type "B"; AGH-hydrogenated cottonseed oil; AGI-interesterified cottoseed oil; PMD-deodorized palm oil; PME-palm stearin; PMO-palm olein; PMH-hydrogenated palm oil; PKR-refined palm kemel oil; PKE-palm kernel stearin; BBD-deodorized babassu oil; BBH-hydrogenated babassu oil.

C8:0 - Caprilic acid

C10:0 - Capric acid

C12:0 - Lauric acid

C14:0 - Myristic acid

C16:0 - Palmitic acid

C16:1 - Palmitoleic acid

(a) Unidentified: probably trans isomer and/or positional of C18:1

(b) Unidentified: probably trans isomer and/or positional of C18:2

(c) Unidentified
C18:1 - Oleic acid

C18:2 - Linoleic acid

C20:0 - Arachidic acid

C18:3 - Linolenic acid 
Softening points varied from $20.1^{\circ} \mathrm{C}$ to $58.4^{\circ} \mathrm{C}$, for palm olein and hydrogenated palm oil, respectively. These values indicate a large range of melting point for the samples studied. This measurement was not done for soybean and cottonseed oils because this method does not apply to these samples due to their low melting points, -23 to $-20^{\circ} \mathrm{C}$ for soybean oil and -2 to $2^{\circ} \mathrm{C}$ for cottonseed oil (Weiss, 1980)

Figures 1 to 14 show DSC melting curves obtained. Melting range and DSC curve shape result from combined effects between fatty acid composition, polymorphism and thermal history (Kaisersberger, 1989). Soybean oil has a characteristic curve about $-25^{\circ} \mathrm{C}$ and its melting occurs at temperatures below $0^{\circ} \mathrm{C}$ (figure 1). In relation to hydrogenated soybean oils, there is a broadening of the curves and their moving to higher temperatures regions (figures 2 and 3 ). Formation of trans and positional isomers due to hydrogenation resulted in the formation of non-intersoluble triglycerides, increasing the melting range of the samples. The same phenomenon occurs with cottonseed oil and its hydrogenated and interesterified samples (figures 4, 5, and 6). Palm oil has a very characteristic curve, showing clearly its two component fractions, separated by an exothermic peak. (figure 7). Hydrogenated palm oil sample shows two peaks, corresponding to $\alpha$ and $\beta$ polymorphic forms (figure 8). Palm olein (figure 9 ) shows only one peak, corresponding to the lowest temperature peak observed in palm oil while palm stearin (figure 10) shows a similar profile to that one of palm oil, showing two peaks. Palm kernel (figure 11) shows only one peak and a limited melting range. Palm kernel stearin (figure 12) has the same DSC profile of palm kernel, but its curve is sharper and is located at higher temperature, indicating a small melting range. Babassu oil (figure 13) has a similar profile of palm kernel oil, both with high concentrations of lauric acid (see table I). Hydrogenated babassu (figure 14) oil has a greater melting range, due to the formation of trans and positional isomers, as already commented about hydrogenated soybean and cottonseed oils.

Onset, peak temperatures and melting point temperatures obtained by DSC melting curves and AOCS Softening point values are shown in table II. When comparing DSC melting point values with softening point ones, those obtained by DSC technique are always higher than softening point ones, with differences ranging from 2.2 to $9.3^{\circ} \mathrm{C}$, with average values of $5.2^{\circ} \mathrm{C}$. Correlationship between the temperatures obtained by the two techniques was calculated as 0.9856 , considered high and indicating good relationship between the two techniques. These results agree with those obtained by Deman et al., (1983) which compared Mettler dropping point and DSC melting points. DSC melting points were generally considerably higher than the Mettler dropping points.

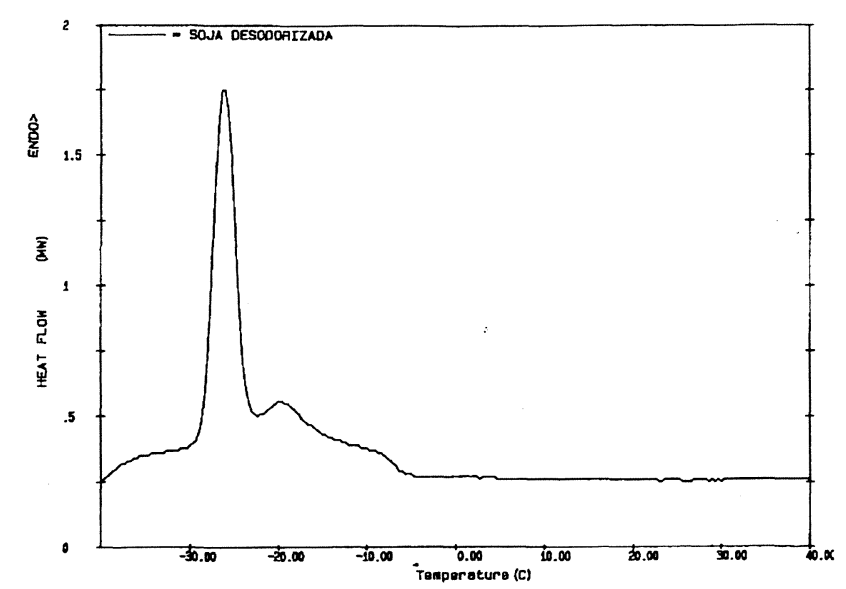

Figure 1

DSC melting curve for deodorized soybean oil

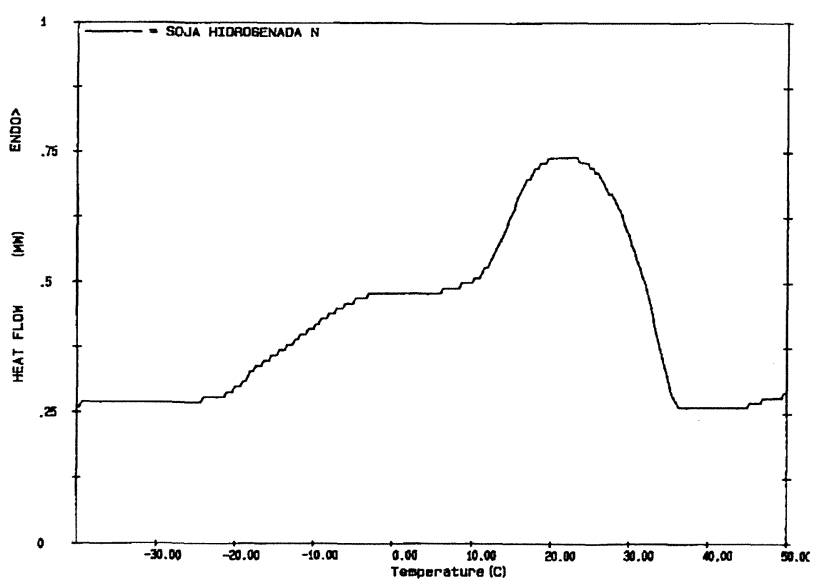

Figure 2

DSC melting curve for type «N» hydrogenated soybean oil

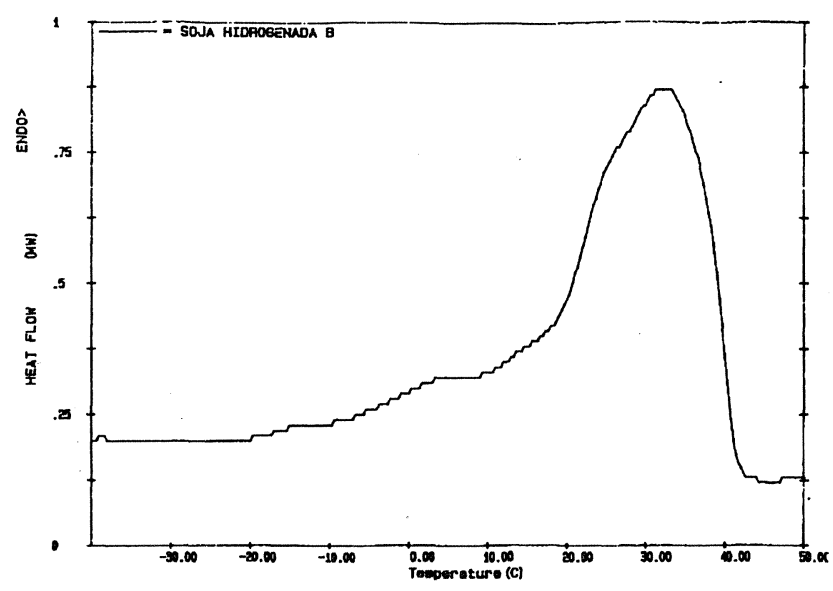

Figure 3

DSC melting curve for type "B" hydrogenated soybean oil 


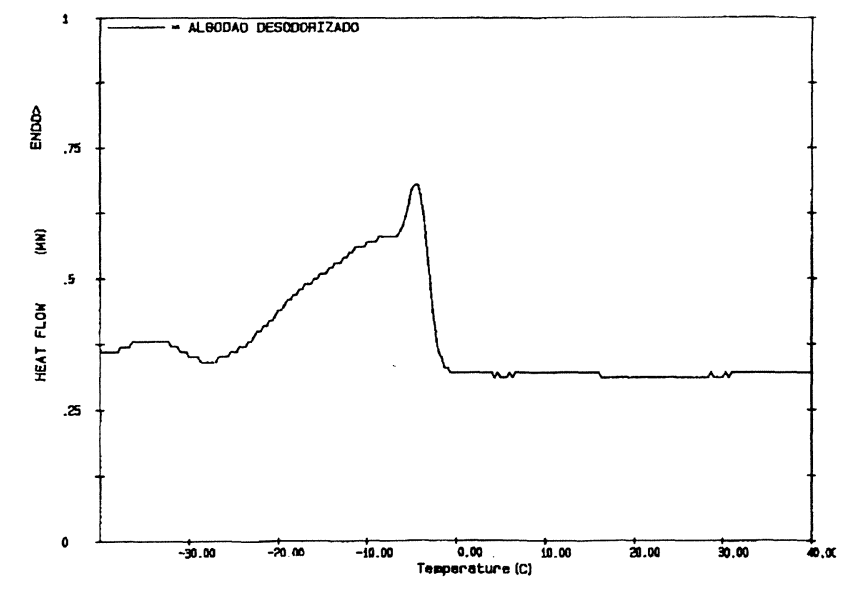

Figure 4

DSC melting curve for deodorized cottonseed oil

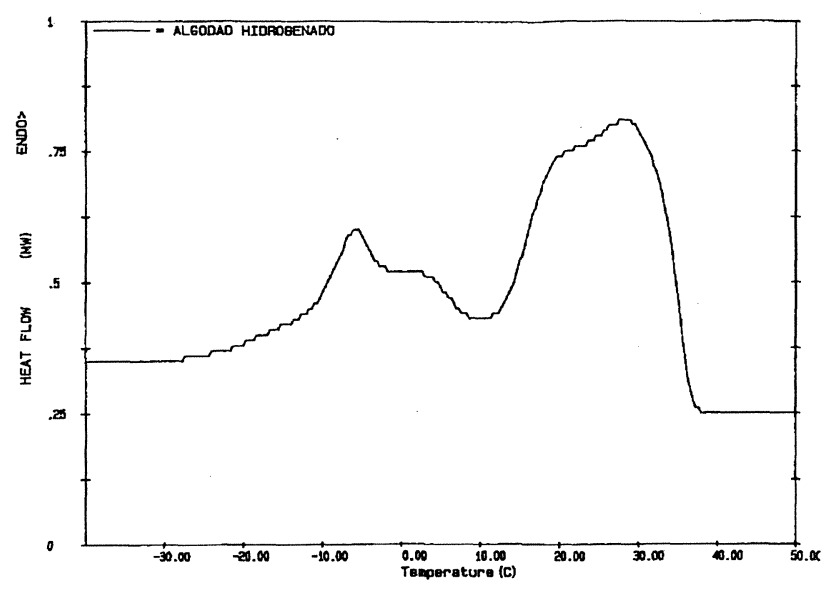

Figure 5

DSC melting curve for hydrogenated cottonseed oil

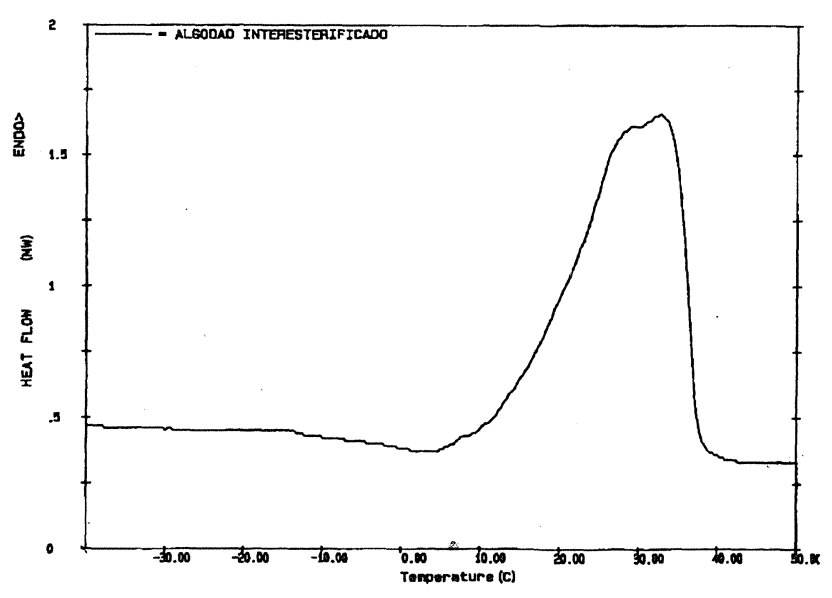

Figure 6

DSC melting curve for interesterified cottonseed oil

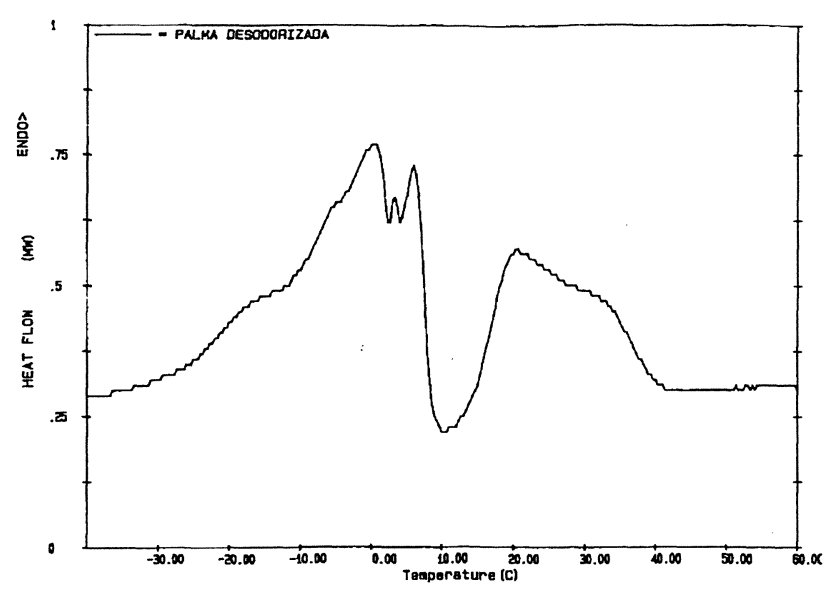

Figure 7

DSC melting curve for deodorized palm oil

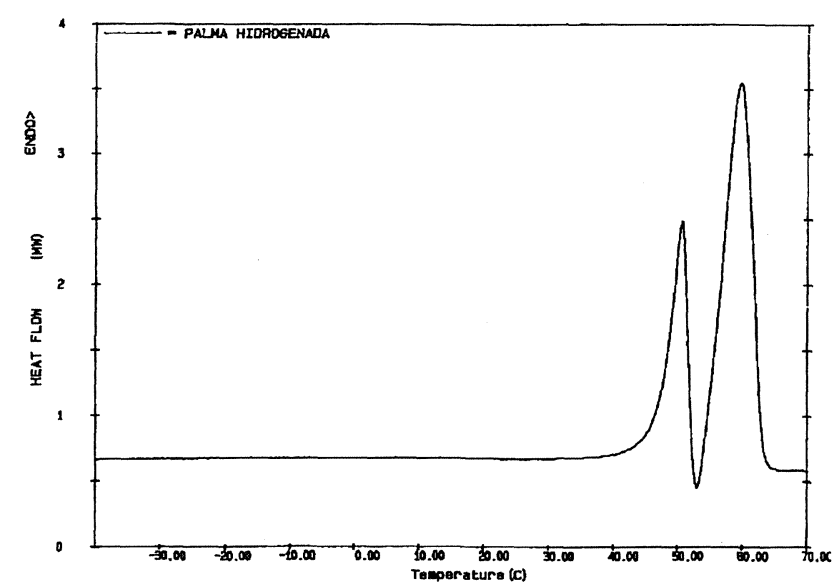

Figure 8

DSC melting curve for hydrogenated palm oil

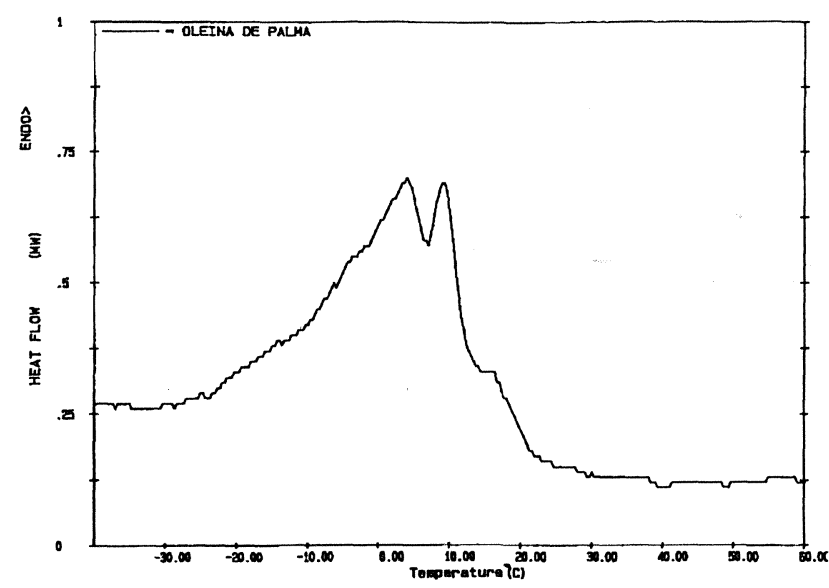

Figure 9

DSC melting curve for palm oil 


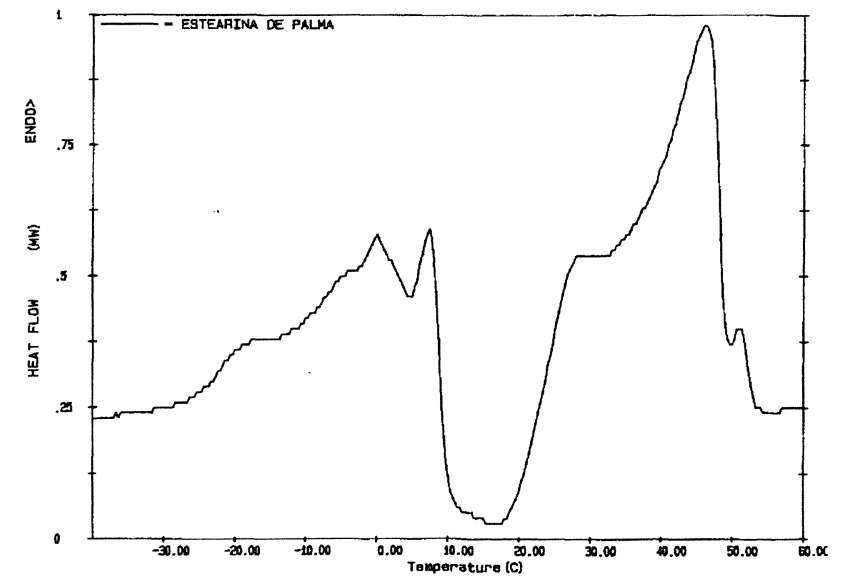

Figure 10

DSC melting curve for palm stearin

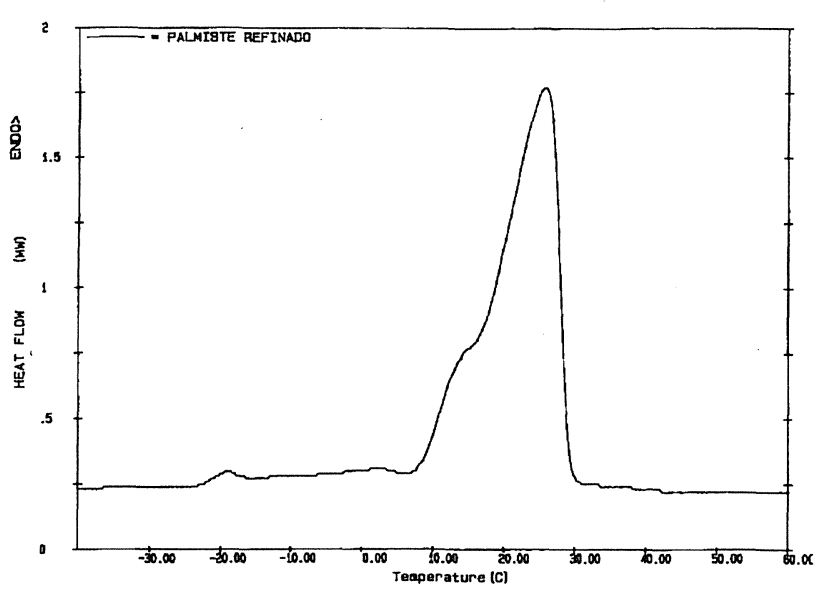

Figure 11

DSC melting curve for refined palm kernel oil

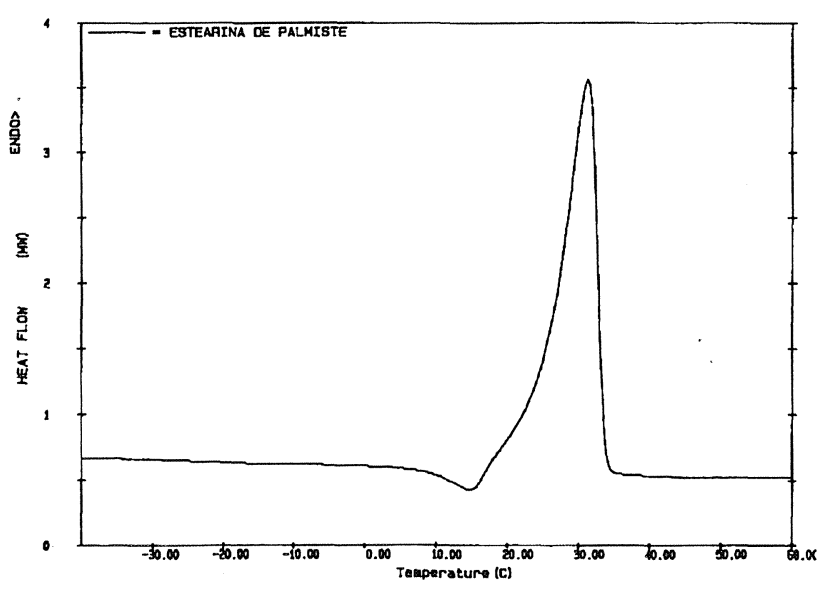

Figure 12

DSC melting curve for palm kernel stearin

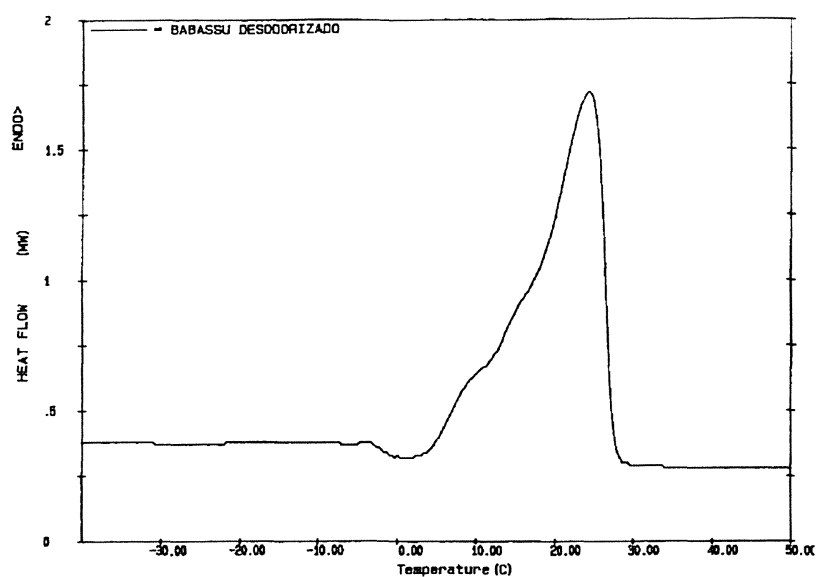

Figure 13

DSC melting curve for deodorized babassu oil

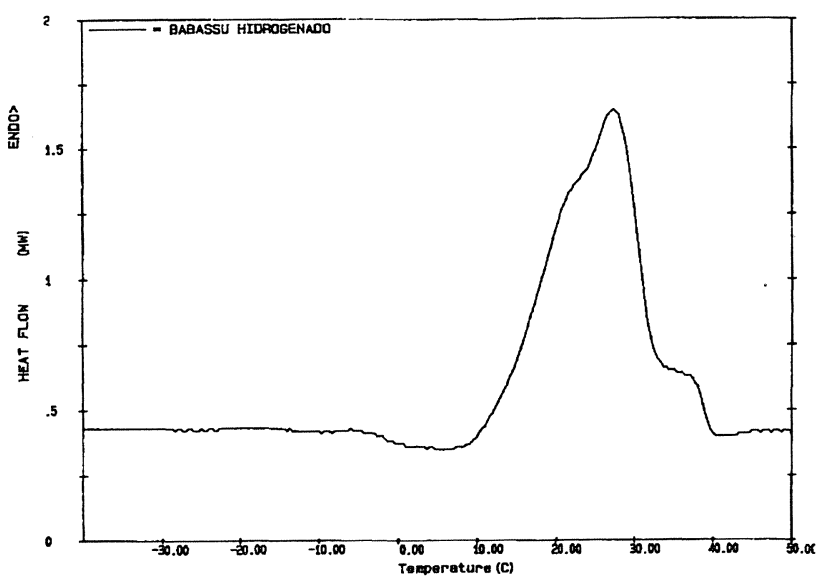

Figure 14

DSC melting curve for hydrogenated babassu oil

Figure 15 shows a graphical comparison between differences of melting points and other characteristic temperatures obtained by DSC melting curves and softening point values. If onset temperatures were considered, differences between these temperatures and softening point ones are bigger, because onset temperatures were recorded when the fat began to melt, while in softening point they had melt more than this point recorded by DSC. When comparing peak temperatures obtained by DSC with softening points, we can observe that the former are higher than those obtained by DSC, except for hydrogenated palm sample. Big differences can be seen between deodorized palm oil and palm olein. This fact occurs because peak temperature is recorded as the temperature of the main peak, when curve shows more than one. In this case, main peak of both samples was located in a region where temperature was not sufficient to melt the sample in the same point of that recorded by softening point. 
Table II

Characteristic temperatures obtained by DSC melting curves and AOCS softening point values

\begin{tabular}{lcccc}
\hline Sample & $\begin{array}{c}\text { Onset } \\
\text { temperature } \\
\left({ }^{\circ} \mathrm{C}\right)\end{array}$ & $\begin{array}{c}\text { Peak } \\
\text { temperature } \\
\left({ }^{\circ} \mathrm{C}\right)\end{array}$ & $\begin{array}{c}\text { Melting } \\
\text { point } \\
\left({ }^{\circ} \mathrm{C}\right)\end{array}$ & $\begin{array}{c}\text { Softening } \\
\text { point } \\
\left({ }^{\circ} \mathrm{C}\right)\end{array}$ \\
\hline SOD & -28.6 & -26.1 & -5.8 & - \\
SON & 6.9 & 19.8 & 36.8 & 32.0 \\
SOB & 15.0 & 32.5 & 42.7 & 37.3 \\
AGD & -9.9 & -4.5 & -0.5 & - \\
AGH & 10.9 & 27.8 & 38.4 & 32.7 \\
AGI & 15.5 & 32.7 & 42.8 & 36.4 \\
PMD & -18.6 & 0.2 & 41.3 & 36.2 \\
PME & 2.3 & 46.2 & 54.5 & 49.8 \\
PMO & -15.5 & 4.0 & 29.4 & 20.1 \\
PMH & 54.4 & 59.7 & 64.9 & 58.4 \\
PKR & 13.6 & 25.8 & 30.6 & 28.4 \\
PKE & 24.2 & 31.3 & 34.8 & 31.7 \\
BBD & 13.8 & 24.4 & 28.9 & 24.4 \\
BBH & 12.3 & 27.3 & 40.4 & 35.5 \\
\hline
\end{tabular}

SOD - deodorized soybean oil; SON - hydrogenated soybean oil type "N"; SOB - hydrogenated soybean oil type "B»; AGD deodorized cottonseed oil; AGH - hydrogenated cottonseed oil; AGI - interesterified cottonseed oil; PMD - deodorized palm oil; PME - palm stearin; PMO - palm olein; PMH - hydrogenated palm oil; PKR - refined palm kernel oil; PKE - palm kernel stearin BBD - deodorized babassu oil; BBH - hydrogenated babassu oil.

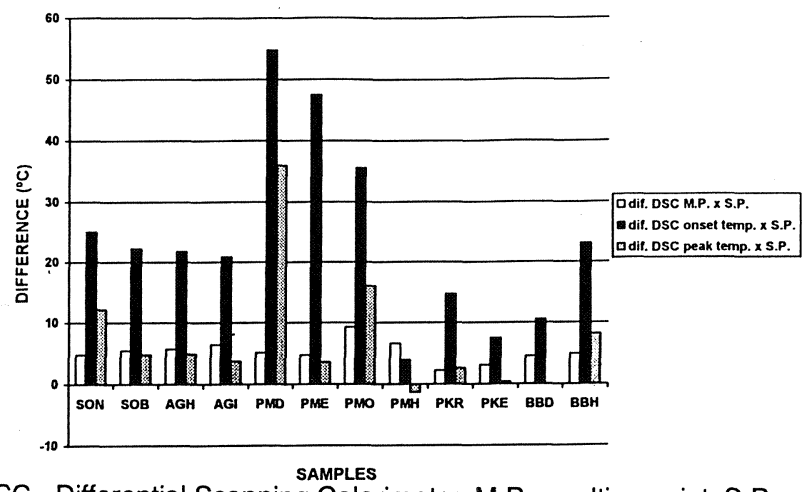

DSC - Differential Scanning Calorimetry; M.P. - melting point; S.P. - softening point.

SOD - deodorized soybean oil; SON - hydrogenated soybean oil type "N"; SOB - hydrogenated soybean oil type "B»; AGD deodorized cottonseed oil; AGH - hydrogenated cottonseed oil; $A G I$ - interesterified cottonseed oil; PMD - deodorized palm oil; PME - palm stearin; PMO - palm olein; PMH - hydrogenated palm oil; PKR - refined palm kernel oil; PKE - palm kernel stearin; BBD - deodorized babassu oil; BBH - hydrogenated babassu oil. Figure 15

Comparative graphic of differences between temperatures obtained by DSC technique and AOCS softening point values

\section{CONCLUSIONS}

These results show that DSC is a accurate technique, which can measure the temperature when fat is completely in the liquid state. When measuring by softening point technique, an empirical method, in the point of measurement crystals are not melted completely, leading to lower values. Besides, by DSC technique it is possible to determine melting point of liquid oils such as soybean and cottonseed oils. DSC melting curves are also obtained, which is very useful to observe the melting range of the sample.

\section{ACKNOWLEDGEMENTS}

The authors acknowledge the financial support given by CNPq (Conselho Nacional de Desenvolvimento Científico e Tecnológico, Brasília, Brasil) and FAPESP (Fundação de Amparo à Pesquisa do Estado de São Paulo, São Paulo, Brasil).

\section{REFERENCES}

AOCS (1988)._- «Official Methods and Recommended Practices of the American Oil Chemists' Society». 3rd. ed., Champaign.

Cebula, D.J.; Smith, K.W. (1991).— «Differential Scanning Calorimetry of Confectionery Fats. Pure triglycerides: effects of cooling and heating rate variation».-J. Am. Oil Chem. Soc. 68: 591-595.

Chaiseri, S.; Dimick, P.S. (1995)._- «Dynamic crystallization of cocoa butter. II Morphological, thermal and chemical characteristics during crystal growth.».-J. Am. Oil Chem. Soc. 82: 1497-1504.

Deman, J.M.; Deman, L.; Blackman, B. (1983).«Melting-point determination of fat products».-J. Am. Oil Chem. Soc. 60: 15-18

Deman, L.; Deman, J.M.; Blackman, B. (1991).— «Physical and textural characteristics of some North American shortenings". J. Am. Oil Chem. Soc. 68: 63-69.

Dodd, J.W.; Tonge, K.H. (1987)._- «Thermal methods».John Wiley and Sons, London.

Hartman, L \& Lago, R. C. (1973).- «Rapid determination of fatty acid methyl esters from lipids".-Lab. Practice 22(8): 475-476, 494.

Kaisersberger, E (1989).- «DSC investigations of the thermal characterization of edible fats and oils".Thermochim. Acta 151: 83-90.

Kanematsu, H.; Kinoshita, Y.; Niiya, I.; Matsumoto, T. (1979a).- «Automatic melting point determination of edible solid fats. IV. Mettler softening points of solid fats".-J. Japan Oil Chem. Soc. (Yukagaku) 28: 180-184

Kanematsu, H.; Kinoshita, Y.; Niiya, I.; Matsumoto, T.(1979b)._- «Automatic melting point determination of edible solid fats. V. Melting point of mixed fats and plastic fat products".-J. Japan Oil Chem. Soc. (Yukagaku) 28:344-347

Kanematsu, $H_{\text {.; }}$ Kinoshita, Y.; Niiya, I.; Matsumoto, T. (1981).— «Automatic melting point determination of edible solid fats. VI. Open-tubed melting point using the Elex apparatus".-J. Japan Oil Chem. Soc. (Yukagaku) 30: 881-883.

Kawada-T; Suzuki-K; Yokomizo-K; Kanematsu-H; Hirata-Y; Shikama-T; Sakata-M; Mori-H; Takeya-K; Abeshima-T (1985).- «Softening point determination by the ring and ball method".-J. Japan Oil Chem. Soc. (Yukagaku) 34: 952-956.

Mertens, W.G. (1973).— «Fat melting point determinations: a review».-J. Am. Oil Chem. Soc. 50: 115-119

Siew, W.L.; Ong, A.S.H.; Oh, F.C.H.; Berger, K.G. (1982)."Critical aspects of slip melting point measurements". PORIM Bull. 4: 1-18.

Weiss, T.J. (1980).—- «Food oils and their uses».-2nd. Ed.-The AVI Publishing Company, Inc., Westport, (Connecticut), p.27-28. 